\title{
Adolescent Offending and the Segregation of Poverty in Urban Neighbourhoods and Schools: An Assessment of Contextual Effects from the Standpoint of Situational Action Theory
}

\author{
Lieven Pauwels \\ Department of Criminal Law and Criminology, Ghent University, 9000 Gent, Belgium \\ Correspondence should be addressed to Lieven Pauwels, lieven.pauwels@ugent.be
}

Received 20 June 2011; Accepted 24 August 2011

Academic Editor: Karen F. Parker

Copyright ( 2011 Lieven Pauwels. This is an open access article distributed under the Creative Commons Attribution License, which permits unrestricted use, distribution, and reproduction in any medium, provided the original work is properly cited.

\begin{abstract}
Contextual research on adolescent offending is primarily based on the idea that residential areas provide a major ecological setting that (indirectly) shapes observed differences in adolescent offending. The social disorganisation/collective efficacy perspective has tried to explain why structural disadvantage of residential areas affects residents' involvement in offending. On the other hand, contextual research has also been conducted within the school setting. This separate contextual approach is problematic as it does not reflect the reality of adolescents' lives. Adolescents are exposed to different ecological settings. They are also exposed to many other settings that may provide opportunities to offend, as outlined in the situational action theory (SAT) of crime causation. This study contributes to the literature on the urban context of offending in three ways. First, the effects of adolescents' residential neighbourhood and school context on adolescent offending are assessed simultaneously. Second, this study elaborates on SAT from a cross-level point of view. Third, this contribution makes use of non-hierarchical multilevel modelling, which is a statistically correct method of testing hypotheses that involve multiple contexts. Our study revealed the existence of small contextual effects of school-level disadvantage, whereas the effect of neighbourhood-level disadvantage is entirely due to neighbourhood composition.
\end{abstract}

\section{Introduction and Goal of the Present Study}

The idea that the characteristics of a context, that is, collective structures, influence the behaviour and attitudes of individuals through processes of socialisation is rooted deep in classical sociological writing [1]. Sufficient evidence exists for the fact that offending does not develop in a vacuum. It is commonly acknowledged that one must always take into account the impact of ecological settings (such as neighbourhoods and schools) when studying adolescent offending [2]. Out of all setting characteristics, the negative effects of neighbourhood- and city-level variation in ecological disadvantage (poverty or the concentration of poor people in urban areas) have been studied most intensively [3]. The attention that is given to the effects of ecological disadvantage is multidisciplinary and focuses on negative outcomes ranging from the low birth weight of newborn babies to problem behaviours such as bullying, adolescent offending $[4,5]$, and even the willingness to report offences in self-report studies [6]. In this study, we examine whether and how both neighbourhood-level and school-level disadvantages affect adolescent offending, a classic theme in urban sociology that has been studied extensively since Shaw and McKay published their magnum opus in 1942. Shaw and McKay consistently observed higher rates of offenders in poor urban areas between the 1920s and the 1940s. The authors concluded that structural disadvantage sets the stage for a decrease in neighbourhood cohesion. This would ultimately lead to a state of social disorganisation. Poor neighbourhoods are less effective in controlling the behaviour of adolescents and become less resistant to the invasion of criminal subcultures. Therefore, higher levels of (adolescent) offenders were observed in disadvantaged neighbourhoods. This was a prominent finding at the time, 
when criminology was still dominated by biological and psychological determinism. Nowadays, we can still observe the covariance of offender rates with neighbourhood-level measures of disadvantage $[7,8]$. Scholars have extended the social disorganisation perspective to the school level, for example, [9]. Intuitively, based on common sense, and for theoretical reasons, observed neighbourhood- and schoollevel differences in offending are believed to be mediated by individual characteristics such as parental monitoring, the adolescent's attachment to his or her school and parents, the propensity to offend, and situational characteristics, such as the daily routines and lifestyles of adolescents. Using cross-nested multilevel models, we simultaneously evaluate the independent effects of both neighbourhood- and school-level disadvantage on individual differences in serious offending. One common criticism of multilevel studies is that many of them lack a theoretical background [9]. Therefore, the situational action theory (SAT) of crime causation [1012 ] is explicitly used as a theoretical framework with which to study the effects of neighbourhood- and school-level disadvantage on serious offending. This recently developed theory stresses the role of individual and contextual characteristics in shaping adolescent offending. SAT provides mechanisms that may explain why adolescents who live in disadvantaged areas or go to disadvantaged schools exhibit higher levels of offending than adolescents who do not live in disadvantaged neighbourhoods or go to disadvantaged schools. Survey data from 2486 (effective sample size) young adolescents who both lived and went to school in Antwerp, Belgium's second largest city and the largest city in the Flemish part of Belgium, were used to simultaneously assess the effects of neighbourhood- and school-level disadvantage on offending. The ultimate goal of the present inquiry is to establish the nature of ecological variation in serious offending by studying the effect of disadvantage at the neighbourhood and school levels and by evaluating the mediating effects of mechanisms derived from SAT.

\section{Neighbourhood- and School-Level Disadvantage and Offending}

In the previous century, neighbourhood-based theories of the geographical distribution of offenders (and offences) were based predominantly on aggregate-level analyses, while individual-level theories of offending were based predominantly on individual traits and social bonds. School-level theories of offending predominantly studied the relationship between pupil-teacher relationships and offending [13]. Since the early 1990s, more attention has increasingly been paid to the integration of individual and ecological characteristics in explanations of offending [14]. These attempts should be interpreted within the context of a growing fear of the negative consequences of the increasing levels of segregation of poor people in some neighbourhoods and poor pupils in some schools. This phenomenon has been observed in the USA and also in Europe, albeit on a smaller scale. In addition, the study of contextual effects was stimulated by statistical innovations such as multilevel data

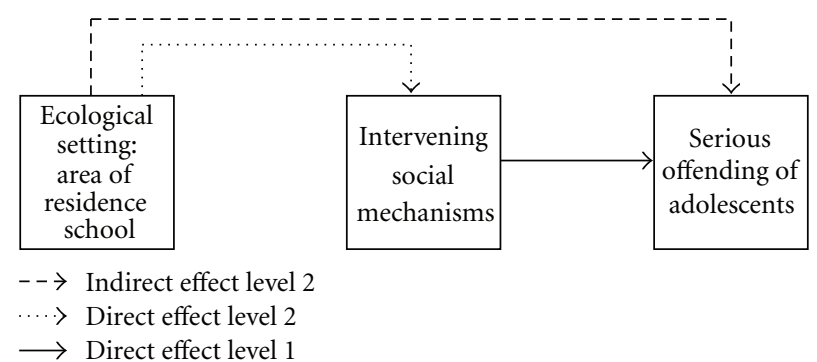

FIGURE 1: Hypothesised effects of ecological structures on serious offending.

analysis. Multilevel analysis is able to statistically differentiate between characteristics that are measured at different levels of analysis. From a historical point of view, criminologists have paid most attention to the ways in which neighbourhoods as collective structures can influence socialisation and offending $[7,15,16]$. From a social disorganisation/collective efficacy perspective [17], the emphasis is placed on the social trust and informal control within neighbourhoods which restrain an individual from offending. In addition to the neighbourhoods in which adolescents live, school is a very important collective structure in their lives. Schoollevel structural and organisational characteristics, together with the school-level social climate, strongly correlate with negative outcomes such as unsatisfactory exam results [1820], school failure [21], and positive outcomes such as psychological well-being [22]. In addition, within the field of criminology, the importance of the school context for offending behaviour was acknowledged a long time ago [9, 23-26]. Indeed, just like areas of residence, schools vary greatly with regard to pupil composition and offending behaviour. As schools are settings that play an important role in providing prosocial socialisation, and as adolescents spend a large part of their free time and share ideas with their peers at school, the question of the importance of differential school composition (i.e., school social structure) with regard to offending is of equally great importance. Criminologists have debated the negative consequences of concentrations of economically disadvantaged adolescents together with collective and subcultural values with regard to offending [27-29]. Research on the school context of offending developed separately from research on the neighbourhood context of offending, despite the fact that some scholars have criticised this bifurcation [30]. As illustrated in Figure 1, ecological disadvantage may affect adolescent offending indirectly through its impact on mechanisms that are directly related to offending. A theoretical framework that fits the goal of the present study well is provided by SAT [1012 ] and will be explained in the following section.

\section{SAT as a Theoretical Framework}

SAT aims to provide a true ecological perspective for the analysis and study of moral action and crime. It is a general theory that seeks to integrate personal and environmental explanatory perspectives within its framework. The theory 
is specifically designed to address the role of the interaction between people and their social environments in crime causation. This action-based theory offers a useful analytical and conceptual framework for studying the mechanisms of crime causation at different levels. Within that framework, offending is considered to be a special case of "moral rule breaking," that is, the breaching of the moral rules represented in criminal laws. The concept of action refers to the actual breaking of criminal laws. SAT stresses the role of the propensity to offend and exposure to criminogenic moral settings as key mechanisms in the understanding of adolescent offending. The concept of propensity refers to the probability that someone will act in a specific way when exposed to particular environmental conditions. The propensity to offend refers to a tendency to see crime as an alternative. ${ }^{1}$ People vary in terms of their level of propensity, meaning that different people react in different ways to the same setting (environmental conditions). People vary not only in their crime propensity, but also in their exposure to different kinds of settings, some of which are more criminogenic than others. People act in response to settings (environmental conditions). According to SAT, whether or not a setting is criminogenic depends on the moral context (relevant moral rules and their enforcement) in which a person encounters opportunities and frictions to which one possible response is a criminal action [10].

Criminogenic settings are external influences within which situations can occur that make offending possible. Such settings can provide moral contexts and deal with the presence of temptation and provocation. The behavioural setting or social milieu in which adolescents spend their time is referred to as the adolescents' activity field. The influence of an individual's exposure to criminogenic settings is assumed to be dependent upon the individual's propensity to offend. SAT does not propose a simple additive model of propensity and exposure, but hypothesises that propensity and exposure interact to determine a person's involvement in crime. Specific combinations of propensity and exposure are likely to produce specific outcomes in terms of a person's engagement in criminal acts. In brief, SAT proposes that the convergence of a person's propensity and exposure initiates a perception-choice process that may lead to offending. ${ }^{2}$ Within the framework of the SAT of crime causation, demographic background variables are considered to be the background of action, and therefore not of causal importance because these variables cannot bring about an effect. ${ }^{3}$ Background variables are important control variables which are used to determine the nature of the relationship between contextual characteristics and individual-level outcomes, and are therefore included in the analyses.

SAT provides us with an extremely interesting framework for elaborating on the study of the effects of disadvantage at the school and neighbourhood levels: we propose that external structural conditions in neighbourhoods and schools may be considered as additional causes of the causes of offending, that is, their effects may be mediated by the propensity to offend and exposure to criminogenic settings and are mainly indirectly related to offending. SAT argues that the characteristics derived from (early) control theories (e.g., [31]) and especially school commitment and parental monitoring are examples of the causes of the causes of offending. The propensity to offend and exposure to criminogenic settings are considered to be the foreground of action. The intersection between crime propensity and exposure to criminogenic settings leads to situations in which the commitment of criminal acts may be seen as an alternative, and decisions to actually commit crimes are taken. In this contribution, we elaborate on SAT in order to study the effect of neighbourhood- and school-level disadvantage on adolescent offending. In contrast to early sociological theories of offending, SAT does not emphasise the role of the structural characteristics of the residential neighbourhood and the school as primary settings, but instead stresses the role of exposure to all kinds of microsettings which provide situational triggers to offend.

\section{Descriptive Research Questions and Hypotheses}

The present study addresses the issue of neighbourhoods and schools on serious offending through a number of descriptive research questions and hypothesiss derived from SAT. Three exploratory research questions are posed in order to assess the partial ecological overlap between adolescents' neighbourhood of residence and school. If adolescents' neighbourhood of residence and school are two partially overlapping settings, then this diversity will be reflected in our sample. Potential overlap may confound the outcomes of neighbourhood contextual studies.

The first exploratory research question is therefore "to what extent do ecological settings overlap?" In other words: are adolescents in Antwerp attending classes in schools that are situated in their own neighbourhoods? Nowadays, pupils are highly mobile and their lives are not necessarily restricted to their area of residence. Adolescents are exposed to many settings.

The second exploratory research question is "to what extent does attending a school in one's own neighbourhood co-vary with neighbourhood disadvantage?" This question is important because it might explain differences in mobility. It may be that adolescents who live in poor areas predominantly attend schools within their areas of residence.

The third exploratory research question is "to what extent is the neighbourhood context of disadvantage reflected in the school context of disadvantage?" This question will provide insight into the reproduction of urban segregation from one context to another. If a certain degree of overlap is found, then it will be necessary to make a clear distinction between settings when answering the question so as to show which setting leaves the strongest mark on adolescents.

From our extended cross-level version of SAT we derived seven hypotheses.

(1) The total variance in offending between individuals can be decomposed into neighbourhood-level, schoollevel and individual-level variance. Hypothesis (1) will be affirmed if a cross-level study on the effects of 
disadvantage at the school level and at the neighbourhood level is meaningful.

(2) Neighbourhood-level disadvantage is positively related to neighbourhood differences in serious offending, while school-level disadvantage is positively related to schoollevel differences in serious offending. Hypothesis (2) is highly suggestive of the existence of contextual effects. However, we must take compositional effects into account in order to understand the nature of the relationship.

(3a) Unique neighbourhood-level variance that is not accounted for by the demographic composition of neighbourhoods is positively related to neighbourhood-level disadvantage.

(3b) Unique school-level variance that is not accounted for by the demographic composition of schools is positively related to school-level disadvantage. In hypothesis (3), we test whether or not the ecological concentration of poor people in urban neighbourhoods and schools has a negative effect on offending, taking into account the demographic composition of the neighbourhood and the school. This hypothesis is a crucial test in the cross-level test of SAT.

(4) The positive effects of school-level disadvantage and neighbourhood-level disadvantage are partially mediated by the protective effects of school commitment and parental monitoring. Hypothesis (4) is derived from SAT, which argues that informal controls are the causes of the causes of offending. These informal controls have negative effects on offending.

(5) The positive ecological effects of disadvantage and the protective effects of parental monitoring and school attachment are further mediated by the propensity to offend. The propensity to offend has a strong direct effect on offending. This hypothesis is directly derived from SAT, which argues that propensity is a key direct mechanism that explains individual differences in offending.

(6) The aforementioned effects are further mediated by exposure to criminogenic moral settings. This hypothesis is also derived directly from SAT, which argues that exposure to criminogenic moral settings is a key mechanism that explains individual differences in offending.

(7) The strength of the impact of exposure to criminogenic moral settings depends mainly on the individual's propensity to offend. This is a key issue which is addressed in SAT. Adolescents who have a low propensity to offend are hardly affected by exposure to criminogenic moral settings, but exposure has a greater effect on those with a higher level of propensity. The theoretical model derived from SAT is presented in Figure 2. The indirect effect of ecological disadvantage is tested by examining the direct effect of ecological disadvantage on offending, and by interpreting what happens when intervening mechanisms are entered into the regression equations.

\section{Previous Contextual Studies of Offending}

Although the importance of context in studies of offending precedes multilevel modelling, the present assessment of contextual studies of offending is restricted to multilevel studies. These use a statistical technique that can separate the effects of ecological settings from the characteristics of individuals who are grouped in these settings. Neighbourhoodbased contextual studies have been inspired by the social disorganisation framework. These studies have yielded inconsistent results, as has been shown in several overviews [3, 8 , 32]. In short, some scholars have failed to demonstrate the effects of neighbourhood-level disadvantage $[7,8,32,33]$. Other scholars have found small but substantive contextual effects $[27,34,35]$. Some scholars have found conditional contextual effects $[15,36,37]$. Similarly, school-based contextual studies of offending (and analogous behaviour such as truancy) have also shown inconsistent results. The literature reviews by Sellström and Bremberg [38] and Gottfredson [9] reveal that the effects of the structural characteristics of schools (e.g., the percentage of poor pupils or pupils of low socio-economic status) on offending vary between countries, from small-sized to nonexistent. In addition, Gottfredson [9] argues that inquiries into the school context of offending have hardly any theoretical foundations. Baerveldt [39] found that all of the differences between schools are due to their differential composition. Similarly, Ousey and Wilcox [40] concluded that school-level variation in violent values reflects nothing more than the values of adolescents. However, some scholars have found substantial contextual effects. Lindström [24] found small but substantial contextual effects on offending, but only for boys and not for girls. Bernburg and Thorlindsson [27] found contextual effects of the school social climate (values) which were independent of the individual values of adolescents. A recent study by Sapouna [25] shows that collective efficacy-the key mechanism in the contemporary version of social disorganisation theorymeasured at the school level is significantly related to bullying. Many explanations have been given for the observed differences between findings. Studies differ a great deal in terms of their population of interest (young children versus adolescents). Studies use different units of analysis (classes versus schools). Differences exist between macrolevel contexts, such as countries, that impede the generalisation of finding. Studies also differ in operational measures that refer to the composition of a setting. ${ }^{4}$ In addition to the aforementioned differences, some other differences should be mentioned that might further blur our insights into contextual effects: thus far, the existing studies also differ in terms of their sampling design and sampling error, the measurement of concepts, measurement error, and model misspecifications. Although the differences between studies seem to outnumber the similarities between studies, it seems that if contextual effects are found, they are usually found when measuring serious offences rather than minor offences. It is clear that contextual multilevel studies await further challenges. 
Neighbourhood-and school-level disadvantage from a cross-level point of view

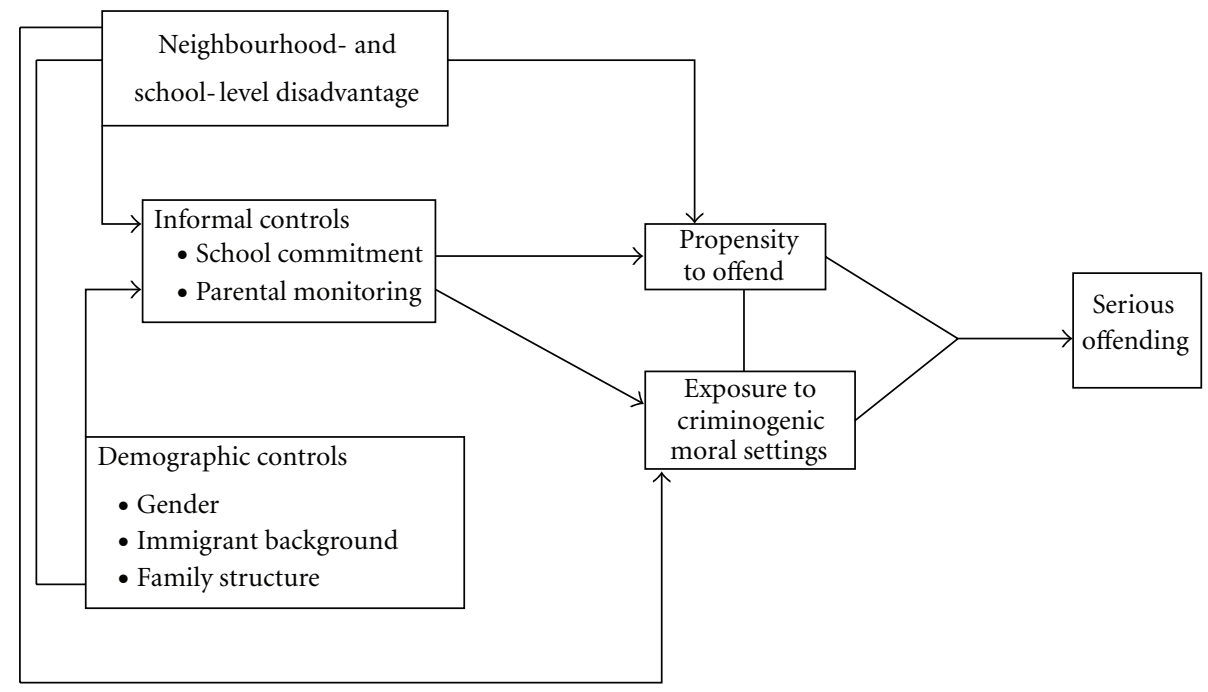

Figure 2: Theoretical model derived from SAT.

\section{Cross-Nested Multilevel Modelling as an Analytical Strategy}

Multilevel modelling is concerned with distinguishing true contextual effects from compositional effects. With regard to the former, we refer to the independent effect of higherlevel variables on outcome variables measured at the lowest level, independent of a number of background variables that make up the composition of the higher-level units. ${ }^{5}$ The effect of a variable at the higher level, independently from the composition, is called the true contextual effect. In neighbourhood studies, contextual effects represent situations in which place characteristics have a direct effect and can be equated with "genuine ecological effects." The latter case refers to the idea that place differences are an artefact of differential socioeconomic composition. This would be the case when poor families decide to live in the poorest neighbourhood. In this case, differential selection is responsible for an observed difference between higher-level units. This is called the selection effect or compositional effect. A purely compositional explanation for observed neighbourhood variation in offending would be that the sort of people whose personal and household characteristics are associated with offending rates tend to live in certain sorts of regions or localities, and this is why the offending rates there are high; such people would be offending at a similar rate wherever they lived, and the place itself has no effect on their frequency of offending. ${ }^{6}$

In a basic two-level hierarchical structure, adolescents may be classified hierarchically by their area of residence. In the present study, adolescents are grouped along more than one dimension. Adolescents are nested in schools and also in the neighbourhood where they live. Identifying contextual effects in such cases is more complex as they may arise from two crosscutting hierarchies, that is, neighbourhoods and schools. This is particularly important if there is a degree of association between the area in which the student lives and the school which he or she attends. If we did not recognise that there are some area effects in addition to school effects which have an impact on adolescent outcomes, we would be dealing with what is often called an "underspecified model." Adolescents take part in several contexts simultaneously, and thus it is rather unclear which setting leaves the strongest mark on them. ${ }^{7}$ For example, a study by Brännström [18] revealed that neighbourhood effects operate through the school context. Thus, failure to account for a "competing ecological setting" might lead to misleading results. In short, one might overestimate the effect of neighbourhood disadvantage. The key question is therefore Which ecological setting leaves the strongest mark on adolescent offending? Is it the residential neighbourhood or the school?

Therefore, we propose that there is inadequate control in a neighbourhood-based contextual model for the important and possibly confounding effects of other ecological settings. The same applies for school-based contextual models that do not take neighbourhoods into account. This is exactly what Oberwittler [41] has already empirically shown. We argue that neighbourhood studies of offending should not ignore schools as competing ecological settings, because young adolescents spend a substantial amount of their time in both settings. In the case of school sampling, schools should be included because the school clustering of adolescents may cause flaws in standard errors if this additional clustering is not taken into account.

The cross-nested multilevel model which is used in the present study decomposes the total variance in offending into between-school, between-neighbourhood, and between-individual variance in offending. Neighbourhood-level characteristics can be used to explain the unique neighbourhoodlevel variance in offending, independently from the demographic characteristics that make up a neighbourhood, while 
Urban Studies Research

school-level characteristics can be used to explain the unique school-level variance in offending, independently from the demographic characteristics that make up schools.

The intraneighbourhood component is the intraclass coefficient that refers to adolescents who live in the same area but attend different schools and therefore provides information about neighbourhood-level variance that is free from school-level variance. ${ }^{8}$ The intraschool component refers to adolescents who attend the same school but live in different areas and therefore provides information about school-level variance that is free from neighbourhood-level variance. $^{9}$

The intracell coefficient is the intraclass coefficient at the "cell level." This coefficient is identical to the intraclass coefficient of a hierarchical model based exclusively on adolescents who attend a school within their residential area. ${ }^{10}$

An empty nonhierarchical multilevel model in its simplest form can therefore be written as follows:

$$
\begin{aligned}
& y_{i(\text { school 1, neighbourhood } k)} \\
& \quad=X \beta_{i}+u_{\text {school }(i)}+u_{\text {neighbourhood }(i)}+u_{\text {adolescent }(i)},
\end{aligned}
$$

where $y_{i}$ is the dependent variable, the frequency of offending of an individual attending one particular school and living in a particular neighbourhood in a given reference period, $X \beta_{i}$ reflects the fixed part of the model and consists of a set of school, neighbourhood, and individual characteristics that need to be estimated, while the $u$-terms reflect the residual error terms for school-, neighbourhood- and individual-level variance. Neighbourhood- and school-level random effects can be explained by neighbourhood-level and school-level variables, respectively. Independent of the possibility of evaluating the impact of partially overlapping settings, an additional advantage of this technique is that it calculates standard errors that fit this clustered data structure [42]. It is also important to note that the data do not need to be balanced over neighbourhoods and schools. Multilevel models can handle imbalance at several levels. Therefore, if some higher-level units contain only very few observations, while other higher-level units contain many observations, multilevel models will make maximum use of the information available.

Nonhierarchical multilevel models have been applied very few times in the history of sociology [18, 20, 4345], and are not commonly applied within the field of criminology. A previous study by Oberwittler [41] is the only study on offending we have found to date that simultaneously assessed the neighbourhood and school contexts of offending. Oberwittler [41] found evidence for the existence of contextual effects of both settings on the frequency of serious offending. His findings have relevant implications for neighbourhood studies: his inquiry revealed that neighbourhood-level variance can be overestimated because part of the observed neighbourhood-level variance is actually due to unmeasured school-level variance. A one-dimensional contextual approach can therefore overestimate a contextual effect.

\section{Data}

The present study used data from the Antwerp Youth Survey, a large-scale cross-sectional self-report survey in Antwerp, one of the major cities in Belgium. ${ }^{11}$ The data were collected from pupils who were in the first cycle of the Belgian secondary educational system between January 2005 and June 2005. ${ }^{12}$ The self-report study was conducted amongst 2486 young adolescents who were cross-nested in 23 schools and 42 neighbourhoods in Antwerp. This study was originally used to test social disorganisation theory [8]. The respondents lived in the city of Antwerp and went to school in Antwerp, one of the major cities in Belgium. The average number of adolescents was 59.19 per neighbourhood and 108.08 per school. Overall, 30\% of all schools in Antwerp that provide education in the first cycle of the Belgian secondary educational system agreed to participate in the study. The questionnaires were distributed by the principal investigator of the present study and fellow researchers at Ghent University. The students completed the questionnaires in a classroom setting in the presence of the author. A detailed assessment of the response rate of the Antwerp adolescent survey in comparison to the population of adolescents that attend classes in Antwerp was a daunting task, as there was no accurate information available on the problem of noncoverage, that is, adolescents living in Antwerp, but attending schools outside Antwerp. There was no complete information regarding noncontact available, as we did not systematically receive valid information on absenteeism from the head teachers. ${ }^{13}$ We can, however, estimate the level of noncooperation in this survey. Noncooperation was estimated by comparing the questionnaires that were handed out and the number of blank questionnaires plus questionnaires consisting of nonsensical answers (response set). Unit nonresponse in the Antwerp survey is thus restricted to the noncooperation of students. The level of noncooperation of the Antwerp students was 7.5\%. The Antwerp sample consisted of $49.4 \%$ boys and $50.6 \%$ girls. Almost half of the respondents had a fully native background (both parents of Belgian descent), $10 \%$ had one parent with an immigrant background, while $45.5 \%$ of the respondents had two parents with an immigrant background. The overrepresentation of immigrants is due to a higher level of participation of schools in inner city areas. Almost $75 \%$ of the respondents were aged $12-14$ years old, while $26.2 \%$ were aged $15-17$ years old. ${ }^{14}$ In total, $15 \%$ of the respondents lived in a single-parent/guardian family and $85 \%$ of the respondents lived with two parents or guardians. The questionnaires were handed out together with envelopes that could be sealed. The final result is a cluster sample at two non-hierarchically structured levels of analysis (individuals cross-nested in schools and neighbourhoods). Despite these restrictions, it is still possible to evaluate the extent to which this sample can be thought of as being representative, at least at the neighbourhood level [37]. ${ }^{15}$ A comparison between aggregate survey-based demographics and aggregate census-tract data revealed rather high correlations between both types of variable. The neighbourhood-level correlation between the percentage of 
TABLE 1: School attendance in own neighbourhood of residence (absolute numbers between brackets).

\begin{tabular}{lccccc}
\hline & $\begin{array}{c}\text { First quartile } \\
\text { neighbourhood } \\
\text { disadvantage }\end{array}$ & $\begin{array}{c}\text { Second quartile } \\
\text { neighbourhood } \\
\text { disadvantage }\end{array}$ & $\begin{array}{c}\text { Third quartile } \\
\text { neighbourhood } \\
\text { disadvantage }\end{array}$ & $\begin{array}{c}\text { Fourth quartile } \\
\text { neighbourhood } \\
\text { disadvantage }\end{array}$ & Total \\
\hline Not in own area & $80.4(356)$ & $80.8(472)$ & $73.2(407)$ & $70.0(632)$ & $75.1(1867)$ \\
In own area* & $19.6(87)$ & $19.2(112)$ & $\mathbf{2 6 . 8}(149)$ & $\mathbf{3 0 . 0}(271)$ & $\mathbf{2 4 . 9}(619)$ \\
$N$ & $100(443)$ & $100(584)$ & $100(556)$ & $100(903)$ & $100(2486)$ \\
\hline
\end{tabular}

${ }^{*} P<.001$.

adolescents with at least one parent with an immigrant background (outside the EU anno 2007) and the percentage of inhabitants from Morocco and Turkey (census databased indicator if inhabitants with a non-European background) was .818, and the neighbourhood-level correlation between the neighbourhood-level concentration of family disadvantage (survey-based information) and a measure of neighbourhood disadvantage (administrative data) was .581. Both correlations were statistically significant $(P<.05)$. The administrative data refer to the year 2003. Univariate sample descriptive statistics can be found in Appendix A. More detailed comparisons between the sample and the population were not possible due to differences in the way in which the administrative data are organised and the way in which the background characteristics were measured.

\section{Measures ${ }^{16}$}

Self-reported serious offending is an index consisting of three items (self-reported burglary, theft of goods worth more than five euro, and buying stolen goods) that were considered to be the most serious offences in the questionnaire, given the age of the respondents. The alpha was $.644 .{ }^{17}$

Sex was coded as zero for girls and one for boys. Immigrant background was coded as zero when both parents were nonimmigrant and one if at least one parent was born abroad. One-parent family was coded as zero if the respondent was living with two parents and one if the respondent was living in a single-parent family. Household disadvantage is a dummy variable that refers to economic problems within the adolescent's household. ${ }^{18}$ School commitment is an additive index and was measured using three items (Alpha: .652). This scale was adapted from Brutsaert [46]. Parental monitoring was measured using five items (Alpha: .709). Propensity to offend was measured using four items that were derived from the Sampson and Bartusch [47] "legal cynicism" scale. The items measure attitudes which are favourable towards law-breaking, and their alpha is .778. Exposure to criminogenic settings was measured as a combined index that measures: (a) how often adolescents hang out in unsupervised settings such as public car parks, street corners, and the city centre, (b) a peer delinquency scale (alpha: .719), and (c) how frequently they report getting drunk during weekends. The result was a combined risk score. These separate constructs measure different aspects of exposure to criminogenic moral settings and were created following the methodology outlined by Wikström and
Loeber [48]. Exposure to criminogenic moral settings was created in precisely the same way as in the Peterborough study of young adolescents that we used as a key reference [32]. ${ }^{19}$ Neighbourhood disadvantage is the result of a confirmatory factor analysis based on the percentage of unemployed people in the neighborhood, the percentage of people on social welfare, and the percentage of children born into poor families. ${ }^{20}$ School disadvantage is measured by the percentage of adolescents living in a disadvantaged family (see above). This characteristic is the school-level aggregate of the aforementioned background variable.

\section{Descriptive Results}

In this section, all of the descriptive research questions are answered. First, we tried to gain insight in the possible overlap between adolescents' residential neighbourhood and school context. The question "to what extent do ecological settings overlap" can be answered by looking at the percentage of adolescents who go to school in their area of residence.

Only $24.9 \%$ of the respondents attended a school that was located in the neighbourhood where they lived. This answers the first research question. A bivariate analysis revealed that the percentage of adolescents who attended a school in their own neighbourhood was significantly higher in disadvantaged neighbourhoods (third and upper quartile in Table 1). This answers the second descriptive research question. The third descriptive question: "to what extent is the neighbourhood context of disadvantage reflected in the school context of disadvantage" can be answered by looking at Table 2, which reveals the percentage of adolescents who attend a poor school and live in a poor area.

From Table 2, it can be derived that less than 5\% $(4.2 \%)$ of the adolescents who lived in a very affluent neighbourhood attended a school that belonged to the upper quartile of disadvantage. The greater the affluence of a neighbourhood, the higher the probability that adolescents from that neighbourhood will go to a school that has a low score for disadvantage. However, just over one in four adolescents $(27.6 \%)$ who lived in a very highly disadvantaged neighbourhood (upper quartile) also attended a school that was characterised by a very high level of disadvantage. For this group, disadvantage seems to be socially reproduced from the neighbourhood level in the school level. This also means that exposure to conditions of disadvantage varies widely for different types of adolescent. Some adolescents spend time in schools that are not characterised by high 
TABLE 2: Relationship between neighbourhood- and school-level disadvantage ${ }^{21}$ (absolute numbers between brackets).

\begin{tabular}{|c|c|c|c|c|c|}
\hline & $\begin{array}{c}\text { Very low } \\
\text { neighbourhood-level } \\
\text { disadvantage }\end{array}$ & $\begin{array}{c}\text { Low } \\
\text { neighbourhood-level } \\
\text { disadvantage }\end{array}$ & $\begin{array}{c}\text { High } \\
\text { neighbourhood-level } \\
\text { disadvantage }\end{array}$ & $\begin{array}{c}\text { Very high } \\
\text { neighbourhood-level } \\
\text { disadvantage }\end{array}$ & Total \\
\hline $\begin{array}{l}\text { Very high school-level } \\
\text { disadvantage }\end{array}$ & $4.2(29)$ & $6.7(41)$ & $27.2(189)$ & $27.6(136)$ & $15.9(395)$ \\
\hline $\begin{array}{l}\text { High school-level } \\
\text { disadvantage }\end{array}$ & $5.4(37)$ & $4.9(30)$ & $28.1(195)$ & $26.6(131)$ & $15.8(393)$ \\
\hline $\begin{array}{l}\text { Low school-level } \\
\text { disadvantage }\end{array}$ & $47.5(328)$ & $48.8(297)$ & $21.2(147)$ & $24.4(120)$ & $35.9(892)$ \\
\hline $\begin{array}{l}\text { Very low school-level } \\
\text { disadvantage* }\end{array}$ & $42.9(690)$ & $39.6(609)$ & $23.6(164)$ & $21.3(105)$ & $32.4(806)$ \\
\hline$N$ & $100(690)$ & $100(609)$ & $100(695)$ & $100(492)$ & $100(2486)$ \\
\hline
\end{tabular}

TABLE 3: Variance components of empty multilevel models.

\begin{tabular}{lccl}
\hline \multicolumn{2}{c}{ Variance decomposition: disentangling unique between-neighbourhood and between-school variance } \\
\hline $\begin{array}{l}\text { Dependent variable } \\
\begin{array}{l}\text { Self-reported serious } \\
\text { offending }(\%)\end{array}\end{array}$ & $\begin{array}{c}\text { Intraneighbourhood } \\
\text { component }\end{array}$ & Intraschool component & Intracell component \\
\hline$* P<.79^{*}$ & $3.02^{*}$ \\
\hline
\end{tabular}

${ }^{*} P<.001$ calculations based on variance components from Table 4; N: 2294 (listwise deletion).

levels of disadvantage, even though they live in disadvantaged areas.

\section{Multivariate Cross-Nested Analyses of Adolescent Offending}

Table 3 shows the similarity between adolescents with regard to serious offending in empty variance component models. Adolescents who live in the same neighbourhood but attend different schools have almost nothing in common with regard to their level of serious offending. The unique neighbourhood-level variance is completely irrelevant. Only $0.23 \%$ of the total variance in serious offending is attributable exclusively to the neighbourhood level. The unique neighbourhood-level variance was not statistically significant. ${ }^{22}$ On the other hand, $2.79 \%$ of the variance in serious offending can be explained exclusively at the school level. ${ }^{23}$ Adolescents who attend the same school and live in different neighbourhoods are therefore more alike than adolescents who live in the same neighbourhood but attend different schools. Finally, adolescents who attend a school within their residential neighbourhood are most alike with regard to serious offending. For this group, the intracell coefficient was $3.02 \%$. This finding suggests that the more ecological settings adolescents have in common, the more they seem to resemble each other with regard to serious offending. Although these results are statistically significant, the variance components in this Belgian study are remarkably lower than in the USA studies that were mentioned earlier. ${ }^{24}$

The conclusions that the school level leaves a potential mark on adolescent offending and the amount of variance that can be explained at the school level are unaffected by not considering the neighbourhood level. The extent to which the observed ecological clustering is due to the demographical composition and mechanisms derived from SAT can also be derived from the multivariate analyses.

Seven blockwise cross-nested multilevel models were run in order to systematically test and evaluate how ecological settings of disadvantage leave their mark on adolescent offending. These models reflect the hypotheses derived from our cross-level extension of SAT. The findings can be found in Table 4. Each block corresponds to a model and represents a step in the analysis and a hypothesis. Thus, each step makes it possible to compare the hypothesis with the empirical data. Each statistical model consists of a set of fixed parameters (characteristics of individuals and/or neighbourhoods and schools) and random effects (school and neighbourhood intercept variance). Significance testing was carried out using the "deviance" badness-of-fit parameter. This test indicates whether or not each subsequent model fits the observed data better than the previous model [49].25 The analysis in model 1 (empty random coefficient model) contains no explanatory variables, but decomposes the total variance in serious offending into unique individual-, neighbourhood-, and school-level variance. The variance components in model 1 were used to calculate the unique neighbourhoodand school-level variance, as reported in Table 3. From this model, it seems that only school-level disadvantage has the potential to leave its mark on adolescent offending. Model 2 assessed whether or not the ecological variance at the neighbourhood and school levels could be explained by introducing ecological concentrations of disadvantage in both settings. It seems that neighbourhood-level disadvantage has no significant effect on between-neighbourhood 
differences in serious offending. School-level disadvantage does have a significant positive effect on between-school differences in serious offending. School-level disadvantage did leave a mark on adolescent offending. This statistical model, including only higher-level variables, explains $2 \%$ of the total variance in serious offending. ${ }^{26}$

In order to ensure that we did not mistake a compositional effect for a true contextual effect, demographic background characteristics that refer to the composition of neighbourhoods and schools, such as sex, immigrant background, family structure, and household disadvantage, were introduced into model 3 as statistical controls. The contextual effect of school-level disadvantage remained statistically significant, while its individual-level counterpart had no significant effect on serious offending. Therefore, the effect of school-level disadvantage is a true contextual effect. This means that adolescents who have similar background characteristics offend more frequently depending on the concentration of disadvantage at the school level. In our study, disadvantage seems to operate exclusively at the school level. Together, the variables presented in model 3 explain 6\% of the total variance in serious offending.

In model 4, parental monitoring and school commitment were introduced. These informal controls had direct significant effects on individual differences in serious offending, while the effects of the other variables in the model decreased. Informal controls partially mediated the effects of compositional and contextual variables. This model explains $14 \%$ of the total variance in serious offending.

In model 5, the propensity to offend was brought into the equation. The propensity to offend had the strongest independent effect on serious offending and reduced the effects of the other variables included in the analysis. The effect of an immigration background lost all significance. This model explains $16 \%$ of the total variance in serious offending. In model 6, exposure to criminogenic settings was added. Exposure to criminogenic settings is a key mechanism for explaining offending because it reflects adolescents' exposure to tempting and provocative settings during their daily routines. This variable had a strong positive effect on serious offending, and its effect even exceeded that of propensity. This model explains $20 \%$ of the total variance in serious offending. These findings are in line with SAT. Finally, model 7 tested whether or not the strength of the effect of exposure to criminogenic moral settings on offending depends on the adolescent's level of delinquency tolerance. The multiplicative interaction term between the propensity to offend and exposure to criminogenic settings that was found using model 7 is strongly positive and significant. This hypothesis is one major statement which was derived from SAT and cannot be falsified. The model that includes all variables explains $25 \%$ of the total variance in serious offending.

\section{Conclusion and Discussion}

In this inquiry, we simultaneously evaluated the effect of neighbourhood-level and school-level disadvantage on individual differences in serious offending. We elaborated on a theoretical model (SAT) that allowed us to integrate the context of disadvantage at the neighbourhood level and the school level with mechanisms operating at the individual level in order to explain individual differences in offending. In this section, we will summarise the descriptive research questions and testable hypotheses that were derived from SAT in order to explain contextual effects on adolescent offending.

From this study, we know that there is an overlap between the neighbourhoods where adolescents live and the neighbourhoods in which they attend classes. However, this overlap is only partial and seems to be especially true for adolescents living in poor urban neighbourhoods. For these adolescents, disadvantage is cumulative, and this phenomenon deserves more attention in future inquiries. The finding that the homogeneity of adolescents with regard to offending increases as the number of ecological settings they share increases should be analysed more carefully in future research. Our study revealed that a small group of adolescents face different constraints from other groups, especially the group of adolescents who live in disadvantaged areas and attend disadvantaged schools. Differential geographical mobility as well as parental selection bias may lead to the fact that some people who live in disadvantaged areas can "choose" to attend affluent schools outside of the area. Only one in four adolescents seem to face the reproduction of neighbourhood-level disadvantage at the school level. Mobility has previously been mentioned as an important theme in research on crime and delinquency [50], and still deserves more attention. One question that has not been dealt with explicitly in this study, but that follows on from this study, is whether the effects of disadvantage are cumulative or interactive From this study, we only know that adolescents who share multiple contexts of disadvantage are more alike in terms of offending and that schools alone seem to leave a significant mark on adolescent offending. The main aim of this study was to disentangle the school and neighbourhood levels in contextual studies of offending and to detect independent contextual effects of disadvantage at both levels.

We will now turn to the evaluation of the hypotheses that were derived from SAT with regard to how neighbourhoodand school-level disadvantage affects adolescent offending.

(1) The total variance in offending between individuals can be decomposed into neighbourhood-level, schoollevel, and individual-level variance. Hypothesis (1) was confirmed.

(2) Neighbourhood-level disadvantage is positively related to neighbourhood-level differences in serious offending, while school-level disadvantage is positively related to school-level differences in serious offending. Hypothesis (2) can only partially be accepted. Only schoollevel disadvantage affects school-level differences in offending. It is therefore necessary to take multiple contexts into account.

(3a) Unique neighbourhood-level variance that is not accounted for by the demographic composition of 
TABLE 4: Blockwise cross-nested multilevel models.

\begin{tabular}{|c|c|c|c|c|c|c|c|}
\hline $\begin{array}{l}\text { Dependent variable/serious } \\
\text { offending scale }\end{array}$ & Model 1 & Model 2 & Model 3 & Model 4 & Model 5 & Model 6 & Model 7 \\
\hline Fixed effects & \multicolumn{7}{|c|}{ Unstandardised slopes of standardised parameters } \\
\hline \multicolumn{8}{|l|}{$\begin{array}{l}\text { Structural background variables at } \\
\text { level } 1\end{array}$} \\
\hline Sex (Boys coded 1$)$ & & & 0.173 & 0.140 & 0.117 & 0.095 & 0.106 \\
\hline $\begin{array}{l}\text { Immigrant background (both } \\
\text { parents native coded } 0 \text { ) }\end{array}$ & & & 0.085 & 0.055 & 0.036 & 0.056 & 0.060 \\
\hline $\begin{array}{l}\text { One-parent family (one-parent } \\
\text { family coded } 1 \text { ) }\end{array}$ & & & 0.010 & -0.000 & 0.000 & -0.010 & -0.01 \\
\hline $\begin{array}{l}\text { Household disadvantage } \\
(\text { disadvantage coded } 1)\end{array}$ & & & 0.015 & 0.009 & 0.011 & 0.006 & 0.019 \\
\hline \multicolumn{8}{|l|}{ Level 2 characteristics } \\
\hline $\begin{array}{l}\text { Neighbourhood-level } \\
\text { disadvantage }\end{array}$ & & 0.035 & 0.018 & 0.015 & 0.013 & 0.014 & 0.020 \\
\hline School-level disadvantage & & 0.137 & 0.107 & 0.097 & 0.092 & 0.072 & 0.072 \\
\hline \multicolumn{8}{|l|}{ Social mechanisms at level 1} \\
\hline School commitment & & & & -0.111 & -0.053 & -0.013 & -0.014 \\
\hline Parental monitoring & & & & -0.230 & -0.179 & -0.116 & -0.105 \\
\hline Propensity & & & & & 0.181 & 0.107 & 0.099 \\
\hline $\begin{array}{l}\text { Exposure to criminogenic } \\
\text { settings }\end{array}$ & & & & & & 0.268 & 0.186 \\
\hline $\begin{array}{l}\text { Propensity* exposure to } \\
\text { criminogenic settings }\end{array}$ & & & & & & & 0.212 \\
\hline \multicolumn{8}{|l|}{ Random effects } \\
\hline Unique individual-level variance & 1.028 & 1.030 & 0.996 & 0.913 & 0.890 & 0.843 & 0.799 \\
\hline $\begin{array}{l}\text { Unique neighbourhood-level } \\
\text { variance }\end{array}$ & 0.002 & 0.000 & 0.000 & 0.000 & 0.000 & 0.000 & 0.001 \\
\hline Unique school-level variance & 0.029 & 0.005 & 0.002 & 0.004 & 0.003 & 0.001 & 0.000 \\
\hline $\begin{array}{l}\text { Sign: deviance test of model fit } \\
\text { improvement }\end{array}$ & - & $*$ & $*$ & $*$ & $*$ & $*$ & $*$ \\
\hline \multicolumn{8}{|l|}{ Decomposition pseudo- $\mathbf{R}^{2} 27$} \\
\hline Neighbourhood level (\%) & - & 95 & 96 & 91 & 93.5 & 70.56 & 45 \\
\hline School level (\%) & - & 79.56 & 92.18 & 85.72 & 87.04 & 95.39 & 97.80 \\
\hline Individual level (\%) & - & - & 3.02 & 11.12 & 13.35 & 17.94 & 27.34 \\
\hline
\end{tabular}

Note. Bold parameters are statistically significant $(P<.05$ or better). All of the variables have been standardised in order to gain insight into the standardised effects of the regression coefficients.

—: Not applicable (not calculated in the model).

*: Significant improvement in model fit at $P<0.05$.

neighbourhoods is positively related to neighbourhoodlevel disadvantage.

(3b) Unique school-level variance that is not accounted for by the demographic composition of schools is positively related to school-level disadvantage. Hypothesis (3a) is falsified. Hypothesis (3b) can be confirmed. Part of the school-level variation in offending is caused by compositional effects, but the school context of disadvantage plays a role in shaping adolescent offending.

(4) The positive effects of school-level disadvantage and neighbourhood-level disadvantage are partially mediated by the protective effects of school commitment and parental monitoring. Parental monitoring and school commitment are important mechanisms of control that tie adolescents to compliant behaviour and prevent adolescents from committing offences.

(5) The positive ecological effects of disadvantage and the protective effects of parental monitoring and school attachment are further mediated by the propensity to offend. The propensity to offend has a strong direct effect on offending. In line with SAT, the propensity to offend mediates the relationship between the remote causes of offending and the direct causes of offending. This hypothesis can be accepted.

(6) The aforementioned effects are further mediated by exposure to criminogenic moral settings. In line with SAT, exposure to criminogenic moral settings is directly 
TABLE 5: Level 1 Descriptive statistics (listwise deletion for the multivariate analyses).

\begin{tabular}{|c|c|c|c|c|c|}
\hline Variable & $N$ & Mean & Standard deviation & Minimum & Maximum \\
\hline Sex & 2294 & 0.49 & 0.50 & 0.00 & 1.00 \\
\hline Immigrant background & 2294 & 0.54 & 0.50 & 0.00 & 1.00 \\
\hline One-parent family & 2294 & 0.15 & 0.36 & 0.00 & 1.00 \\
\hline $\begin{array}{l}\text { Household } \\
\text { disadvantage }\end{array}$ & 2294 & 0.10 & 0.30 & 0.00 & 1.00 \\
\hline Serious offending & 2294 & 0.36 & 1.17 & 0.00 & 9.00 \\
\hline Parental monitoring & 2294 & 0.00 & 1.00 & -3.40 & 1.23 \\
\hline School attachment & 2294 & 0.00 & 1.00 & -3.35 & 1.74 \\
\hline Propensity to offend & 2294 & 0.00 & 1.00 & -1.34 & 2.36 \\
\hline $\begin{array}{l}\text { Exposure to } \\
\text { criminogenic moral } \\
\text { settings }\end{array}$ & 2294 & 0.00 & 1.00 & -1.12 & 3.33 \\
\hline
\end{tabular}

TABLE 6: Level 2 descriptive statistic.

\begin{tabular}{lccccc}
\hline Variable & $N$ & Mean & $\begin{array}{l}\text { Standard } \\
\text { deviation }\end{array}$ & Min. & Max. \\
\hline $\begin{array}{l}\text { Neighbourhood- } \\
\text { level } \\
\text { disadvantage }\end{array}$ & 42 & 0.00 & 1.00 & -1.07 & 2.85 \\
$\begin{array}{l}\text { School-level } \\
\text { disadvantage }\end{array}$ & 23 & 11.01 & 6.47 & 2.52 & 25.86 \\
\hline
\end{tabular}

related to offending, and the introduction of this mechanism decreases the effects of the aforementioned variables. This hypothesis can be accepted.

(7) The strength of the impact of exposure to criminogenic moral settings depends mainly on the individual's propensity to offend. This hypothesis can be accepted and is in line with previous comparative studies on the interaction between the propensity to offend, exposure to criminogenic settings and offending [51].

What do these findings mean with regard to the study of urban settings and offending? Our findings are in line with many European multilevel studies on adolescent offending which have been mentioned above. Studies that do not use multilevel methods and which do not simultaneously take the school context into account may be flawed. The neighbourhood-level variation in offending is entirely due to compositional effects. From this finding, we raise the question of what causes the segregation of individuals into areas. It is imperative that the processes of segregation are elucidated [52]. Why and how are individuals selectively segregated into ecological settings? We do not know enough about this topic, and we argue that exploratory studies are necessary before one can take up the discussion of context and the behaviour and attitudes of individuals. The school-level variation in offending is not exclusively due to the differential demographic composition of adolescents. School-level disadvantage leaves a small but significant mark on adolescents with regard to offending. This contextual effect is partially mediated by the adolescents' school commitment and parental monitoring and is further mediated by the propensity to offend and exposure to criminogenic moral settings. The variation that has been found at the ecological level of schools and neighbourhoods in the Antwerp context is much lower than the variation previously found in Germany by Oberwittler [41]. These enormous differences between Western-European cities are puzzling. It is important that future studies take country-level differences into account. With regard to the differences in the contextual effects of ecological characteristics on behavioural and attitudinal outcomes, another possible explanation could be the poor differentiation between the long-term influences of ecological settings and the short-term situational influences of setting characteristics. Wikström et al. [11] suggest distinguishing between long-term influences and the short-term situational influence of setting characteristics on offending.

However, in general, it seems that genuine contextual effects of neighbourhood characteristics on offending are somewhat overestimated in the European context. One possible lesson to be learned from this study is that scholars should stop focusing on the neighbourhoods where adolescents live. In order to assess contextual effects on adolescent offending, it is of utmost importance to know where adolescents really spend their time.

Our results are highly suggestive of the fact that the prevention of adolescent offending has little to gain from redistributing the neighbourhood composition of disadvantage. On the other hand, the school-level concentration of disadvantage did affect adolescent offending. The segregation of adolescents from poor households in schools should therefore be avoided from the point of view of crime prevention. Although a school-level contextual effect exists, the contextual effect on adolescent offending in the Antwerp context should not be overestimated. We found that the contextual effect of school-level disadvantage is partially mediated by informal controls, such as school attachment and parental monitoring (see also [53]), and is further reduced by crime propensity and exposure to criminogenic moral settings [54]. These mechanisms that link the macrolevel context of the school with the microlevel 
Table 7

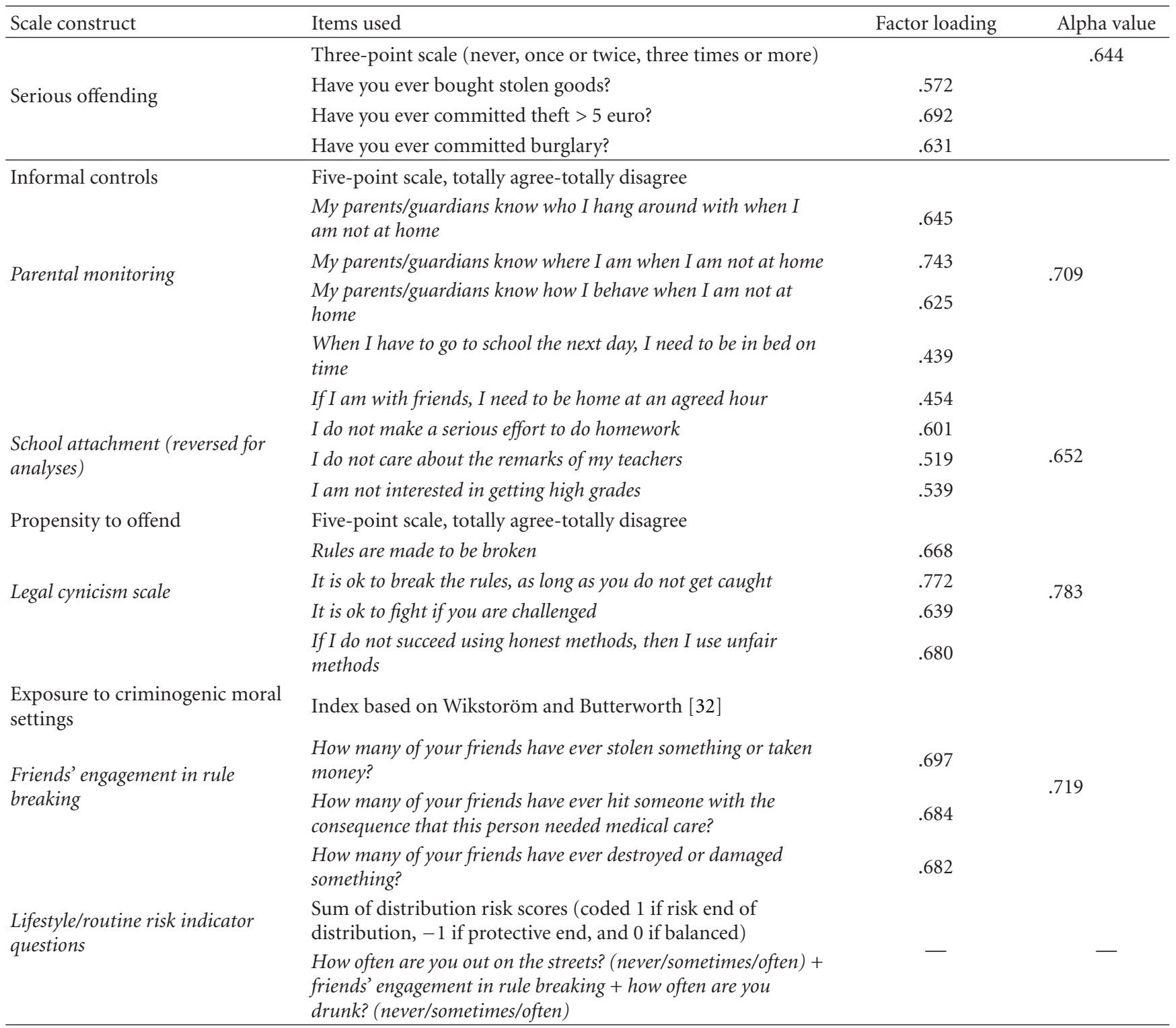

context of the individual were derived from SAT. In the urban context of Antwerp, schools are much more segregated than neighbourhoods with regard to individual-level characteristics that are considered to be causes of offending or causes of the causes of offending. The mechanisms derived from SAT are strongly related to adolescent offending. Exposure to criminogenic moral settings is directly related to adolescent offending, especially for individuals with high levels of the propensity to offend. This is an important finding, because it stipulates that spending leisure time in unstructured and unsupervised settings helps to shape adolescent offending. Scholars who focus on the social disorganisation/collective efficacy perspective may want to readdress the issue of the contextual effects of neighbourhood characteristics on offending by focusing on the settings where adolescents really spend most of their time. This would be a very complex task. The concept of exposure to criminogenic moral settings as outlined in SAT is useful. Urban settings that affect adolescents are probably much smaller than neighbourhoods and schools and not as easy to define and measure using traditional definitions, such as census tracts. The major difference between SAT and the classical contextual theories is that SAT uses a broader definition of settings and does not focus on the neighbourhood where the subject lives. Thus, SAT challenges the studies of offending in urban settings in the 21 st century.

Finally, some cautionary remarks must be made. First of all, through the cross-sectional design of the present study, one can ultimately only view the strength of ecological structures in relation to individual differences in offending. It must be kept in mind that no real causal effect has been demonstrated. Other research designs, such as experimental designs in which similar adolescents are assigned to different experimental neighbourhood conditions, and in which their 
involvement in offending is monitored, may be better from a methodological point of view. The present study tested statements derived from a cross-level integration of SAT. Studies in this vein can only suggest directions for the prevention of urban youth crime. An interesting and ongoing debate among scholars deals with how neighbourhood interventions should be evaluated [52, 55]. It has been suggested by Sampson [52] that all evaluations of crime prevention programmes in schools and neighbourhoods should be conducted at the level at which these interventions were imposed. Issues concerning the beneficial effects of the redistribution of adolescents at the neighbourhood and school levels deserve far more attention than they have thus far received in contemporary criminology.

From this study, it follows that adolescents who grow up in a family context of disadvantage offend more frequently when they are concentrated in schools. Intervention studies should give us more insight into the consequences of intervening at the school level with regard to (a) the schoollevel consequences of offending and $(b)$ consequences at the individual level.

The empirical finding that the strength of the influence of exposure to criminogenic settings (lifestyle risk) on offending depends on a person's level of propensity to offend also has implications for further contextual studies of offending. Future studies should also look at other contexts, and then the residential neighbourhood and the school which the subject attends. This can be done by measuring the settings in which adolescents are present when they offend and the settings in which they spend most of their time. From the identified interaction effect between exposure to criminogenic moral settings and the propensity to offend, it follows that the influence of the ecological setting which adolescents are exposed to during their leisure time is not equally relevant for all kinds of adolescents. Therefore, future studies should take into account what kinds of urban settings are important for certain kinds of adolescents. Only a more detailed analysis can improve our insights into the ecological and individual causes of law breaking.

\section{Appendices}

\section{A. Nonhierarchical Multilevel Analysis of Descriptive Statistics}

See Tables 5 and 6.

\section{B. Measurement of Scale Constructs}

See Table 7.

\section{Endnotes}

1. A number of scholars have found empirical evidence that measures of propensity, such as low self-control [56-58] and antisocial values or attitudes which are conducive to the violation of laws $[31,59,60]$, is strongly related to offending.
2. Scholars have found empirical evidence that exposure to criminogenic moral settings, such as spending time with delinquent peers, high frequencies of alcohol consumption, spending less time at home, and spending most of one's free time in unstructured and unsupervised activities, is consistently related to offending [61-66].

3. Thus, in line with Wikström [12], we recognise that differences between groups (e.g., people of the same age or sex) exist. It is even possible to explain the observed differences between such groups, but therefore one should not interpret the relationships between background variables such as age, sex, and immigrant background as causes of offending. It is hard to see how being male is related to offending, unless one identifies and then measures a cause, and not the background variable that is assumed to be related to offending.

4. In this case, it is worth noticing that one cannot only undercontrol for compositional effects but also overcontrol for compositional effects. It is clear that without the guidance of theoretical assumptions that are thoroughly reflected, one can end up under- and overcontrolling for compositional effects. The problem of control variables is a caveat in every multilevel study.

5. The variables at the lower level are included in order to control for the confounding effects of compositional variables.

6. However, even in the case of selection, the selection effect in itself is worth studying in order to increase our knowledge of ecological social processes (see Sampson [52] for a thorough discussion). Selection should be seen not only as a nuisance; it should be studied thoroughly in order to increase our insight into the consequences of segregation and selection at multiple moments in time. What has previously been detected as a selection effect may eventually develop or generate other contextual effects.

7. Some adolescents live in different areas, but attend the same school, while others live in the same area, but attend different schools. Finally, some adolescents attend schools in their area of residence. It can be hypothesised that these different ecological combinations can have different consequences regarding offending. If we assume that one adolescent lives in a problem area, but attends a school that has a highly prosocial climate, would that combination lead to a more favourable outcome than living in a neighbourhood with a highly favourable social climate and attending a school with an unfavourable social climate? This is, however, not the main issue of the current study. The main argument stated above is that different settings may leave their marks on individuals. Thus, we want to know which setting has the potential to leave the strongest traces on adolescent offending. The main goal of this contribution is to establish the nature of ecological variation in serious offending by comparing two ecological settings that have previously been identified as important settings with consequences for adolescent offending. 
8. This coefficient is statistically identical to the intraclass coefficient in a hierarchical model containing only respondents who live in the same area but attend different schools.

9. This coefficient is statistically identical to the intraclass coefficient in a hierarchical model containing only respondents who attend the same school but live in different areas.

10. These adolescents are expected to be more alike than the others because they share more than one ecological setting. By unfolding the total variance in a cross-classified design, one can simultaneously estimate similarities between adolescents based on different school-neighbourhood combinations [44]. In fact, a cross-nested multilevel model is based on all observed neighbourhood-school combinations.

11. Antwerp's population totalled 470,044 persons as of January 2006. On average, there are 2420 inhabitants per square kilometre. In terms of the nationality of Antwerp's population, $13.3 \%$ of its inhabitants are registered as foreigners in the population register. The main nationalities are Moroccan, Dutch, and Turkish. Otherwise, foreign nationals typically come from other EU member states, or from the former Yugoslavia, Russia, the Congo, China, and India. However, these percentages do not fully reflect the ethnic diversity of the city, as a large number of inhabitants of foreign origin have taken Belgian nationality in the past few decades. Overall, the number of inhabitants with a migratory background-that is, foreign nationals or Belgian nationals born with a foreign nationality-represents $26.6 \%$ of Antwerp's population. This percentage has been rising since 2000. Among them, persons of Moroccan origin constitute the largest group, followed by those of Dutch, Turkish, Polish, former Yugoslavian, Indian, Congolese, Jewish, Russian, and West European origins. In total, $18.4 \%$ of the inhabitants with a migratory background are from non-EU countries. Antwerp was chosen as the setting for the present study because of its high level of neighbourhood segregation within the Flemish context. Although Antwerp has the highest level of neighbourhood segregation with regard to unemployment and immigrant concentration in the Flemish context, this level cannot be compared to levels of segregation that have been observed in USA cities such as Chicago. For more details, see Gsir [67].

12. In Belgium, secondary education is provided for adolescents aged 12- 18 and consists of six years, divided into three grades (or "educational cycles") of two years each. The first grade (two years: type A or B) offers a range of general subjects. People enter the secondary school system after six years of education in an elementary school. These students are, on average, 13 years old when they enter the "first educational cycle" and 14 when they leave this cycle.

13. There is a possibility that the adolescents with the highest levels of "serious offending" and the "propensity to offend" were more likely to be absent from school on the days of the survey.

14. Age is a covariate of offending but hardly a cause of offending. Adding age as an additional control variable in the analyses presented below did not affect the results. In fact, we omitted age as a control variable for reasons of parsimony, because age was shown to be completely unrelated to offending in the multivariate analyses.

15. At the school level, this can be done by comparing survey information with official registrations from school inscriptions. We did not do this, because we promised full confidentiality.

16. For a full description of the items and additional factor loadings, see Appendix B.

17. The alpha is rather low, but this is due to the fact that only three items were used. The nine-item delinquency scale used in the original study generated an alpha of 0.81 . It is known that alpha values are affected by the number of items. More serious offences are committed less often by adolescents. It should also be noted that behavioural scales are different from attitudinal scales.

18. An adolescent was seen as "belonging to a disadvantaged household" when no car was reported and when the respondent had heard his or her parent(s) say that "there was sometimes or often no money to buy essential things." As one can question the validity of each indicator separately, we conjunctively combined both indicators in order to be more strict. This measure has some restrictions. It may not be sufficient as a control for the compositional effects of disadvantage at the individual level. Nevertheless, we would highlight the fact that the ecological correlation of that measure with an official measure was sufficiently high.

19. The separate dimensions were trichotomised (risk end of the distribution $>1$ standard deviation above the mean score, balanced between -1 standard deviation and +1 standard deviation, and the protective end of the distribution $<-1$ standard deviation from the mean score).

20. The factor loadings are $.972, .973$, and .834, respectively. The fit indices indicated a good model fit (RMSEA $<0.05$ ) and AGFI $>0.96$.

21. Original metric variables were recoded into categorical variables using quartiles.

22. The calculation of the unique neighbourhood-level variance is as follows: (neighbourhood-level variance/ (neighbourhood-level variance + school-level variance + individual-level variance)).

23. The calculation of the unique school-level variance is done the same way: (school-level variance/(neighbourhood-level variance + school-level variance + individual-level variance)).

24. One might wonder if different results would have been obtained if separate hierarchical linear models had been used to detect ecological variance at the neighbourhood 
and school levels. The answer to this question is yes: the neighbourhood effect would have been overestimated, but unlike the German study by Oberwittler [41], only to a very limited extent. This is because the residential neighbourhood context hardly adds up to the explanation of serious offending in Antwerp. If we had not taken into account school-level variance, we would have found a small but statistically significant amount of neighbourhood-level variance $(0.99 \%)$ in the empty model (see Pauwels [8], for the original hierarchical multilevel models). School-level variance is hardly affected when neighbourhoods are not taken into account $(2.99 \%$ in a hierarchical school contextual model versus $2.79 \%$ in the cross-nested model).

25. The "deviance" parameter is actually a "badness of fit" parameter. The higher the value of this parameter, the less the statistical model fits the observed data.

26. This calculation was carried out as suggested by Snijders and Bosker [49]. Pseudocoefficients of determination cannot be compared with coefficients of determination obtained from OLS regression models. Interpretation should be performed with care. The pseudocoefficients of determination can underestimate the coefficients of determination obtained from OLS regression analyses, which we simulated.

27. The decomposition pseudocoefficients of determinations are very informative: they teach us how much of the variance at each level is explained by the variables in the models. These pseudocoefficients are lower than their counterparts in ordinary least squares (OLSs) regression models, which do not take into account the data structure.

\section{References}

[1] T. Parsons, The Structure of Social Action, The Free Press, New York, NY, USA, 1937.

[2] T. I. Herrenkohl, J. D. Hawkins, I. J. Chung, K. G. Hill, and S. Battin-Pearson, "School and community risk factors and interventions," in Child Delinquents, R. Loeber and D. Farrington, Eds., pp. 211-246, Sage, Thousand Oaks, Calif, USA, 2000.

[3] R. J. Sampson, "Transcending tradition: new directions in community research, Chicago style," Criminology, vol. 40, no. 2, pp. 213-230, 2002.

[4] J. Brooks-Gunn, G. J. Duncan, and J. L. Aber, Neighborhood Poverty: Context and Consequences for Children, vol. 1, Russell Sage Foundation, New York, NY, USA, 1997.

[5] G. J. Duncan and S. W. Raudenbush, "Neighborhoods and adolescent development: how can we determine the links?" in Does It Take a Village? Community Effects on Children, Adolescents, and Families, A. Booth and A. C. Crouter, Eds., pp. 105-136, Pennsylvania State University Press, State College, Pa, USA, 2001.

[6] L. Ann Slocum, T. J. Taylor, B. T. Brick, and F. A. Esbensen, "Neighborhood structural characteristics, individual-level attitudes, and youths' crime reporting intentions," Criminology, vol. 48, no. 4, pp. 1063-1100, 2010.
[7] B. Rovers, De Buurt, een Broeinest? Een Onderzoek naar de Invloed van de Woonomgeving op Jeugdcriminaliteit, Ars Aequi Libri, Nijmegen, The Netherlands, 1997.

[8] L. Pauwels, Buurtinvloeden en Jeugddelinquentie, Een Toets van de Sociale Desorganisatietheorie, Boom Juridische Uitgevers, Den Haag, The Netherlands, 2007.

[9] D. Gottfredson, Schools and Delinquency, Cambridge University Press, Cambridge, UK, 2001.

[10] P.-O. H. Wikström, "Situational action theory," Encyclopedia of Criminological Theory, Sage, London, UK, 2010.

[11] P.-O. H. Wikström, "Crime as alternative: towards a crosslevel situational action theory of crime causation," in Beyond Empiricism: Institutions and Intentions in the Study of Crime, J. McCoard, Ed., pp. 1-37, Transactions, New Brunswik, NJ, USA, 2004.

[12] P.-O. H. Wikström, "The social origins of pathways in crime: towards a developmental ecological action theory of crime involvement and its change," in Testing Integrated Developmental/Life Course Theories of Offending. Advances in Theoretical Criminology, D. P. Farrington, Ed., pp. 211-245, Transactions, New Brunswik, NJ, USA, 2005.

[13] N. Vettenburg and L. Walgrave, "Maatschappelijke kwetsbaarheid, school en verstedelijking," in Jeugdcriminologie. Achtergronden van Jeugdcriminaliteit, I. Weijers and C. Eliaerts, Eds., pp. 183-205, Boom Juridische Uitgevers, Den Haag, The Netherlands, 2008.

[14] D. P. Farrington, R. J. Sampson, and P.-O. H. Wikström, Integrating Individual and Ecological Aspects of Crime, National Council for Crime Prevention (Brå), Stockholm, Sweden, 1993.

[15] F. Peeples and R. Loeber, "Do individual factors and neighborhood context explain ethnic differences in juvenile delinquency?" Journal of Quantitative Criminology, vol. 10, no. 2, pp. 141-157, 1994.

[16] P. H. Tolan, D. Gorman-Smith, and D. B. Henry, "The developmental ecology of urban males' youth violence," Developmental Psychology, vol. 39, no. 2, pp. 274-291, 2003.

[17] R. J. Sampson, "The embeddedness of child and adolescent development: a community-level perspective on urban violence," in Violence and Childhood in the Inner City, J. McCord, Ed., pp. 31-77, Cambridge University Press, Cambridge, UK, 1997.

[18] L. Brännström, Making Their Mark. Disentangling the Effects of Neighbourhood and School Environments on Educational Achievement, Arbetsrapport, Institutet För Framtidsstudier, Stockholm, Sweden, 2007.

[19] H. Goldstein, J. Rasbash, and M. Yang, "A multilevel analysis of school examination results," Oxford Review of Education, vol. 19, pp. 425-433, 1993.

[20] H. Goldstein and P. Sammons, "The influence of secondary and junior schools on sixteen year examination performance: a cross-classified multilevel analysis," School Effectiveness and School Improvement, vol. 8, no. 2, pp. 219-230, 1997.

[21] M. Van Houtte, "Tracking effects on school achievement: a quantitative explanation in terms of the academic culture of school staff," American Journal of Education, vol. 110, no. 4, pp. 354-388, 2004.

[22] B. De Fraine, G. Van Landeghem, J. Van Damme, and P. Onghena, "An analysis of wellBeing in secondary school with multilevel growth curve models and multilevel multivariate models," Quality and Quantity, vol. 39, no. 3, pp. 297-316, 2005. 
[23] J. Fiqueira-McDonough, "School context, gender, and delinquency," Journal of Youth and Adolescence, vol. 15, no. 1, pp. 79-98, 1986.

[24] P. Lindström, Context and Delinquency. Project Metropolitan. Research Report No. 41, Stockholm University, Department of Psychology, Stockholm, Sweden, 1995.

[25] M. Sapouna, "Collective efficacy in the school context: does it help explain victimization and bullying among Greek primary and secondary school students?" Journal of Interpersonal Violence, vol. 25, no. 10, pp. 1912-1927, 2010.

[26] T. L. Parcel, M. J. Dufur, and R. Cornell Zito, "Capital at home and at school: a review and synthesis," Journal of Marriage and Family, vol. 72, no. 4, pp. 828-846, 2010.

[27] J. G. Bernburg and T. Thorlindsson, "Violent values, conduct norms, and youth aggression: a multilevel study in Iceland," Sociological Quarterly, vol. 46, no. 3, pp. 457-478, 2005.

[28] S. Boxford, Schools and the Problem of Crime, Willan Publishing, Devon, UK, 2006.

[29] G. J. N. Bruinsma, "Differential association theory reconsidered: an extension and its empirical test," Journal of Quantitative Criminology, vol. 8, no. 1, pp. 29-49, 1992.

[30] U. Bronfenbrenner, The Ecology of Human Development, Harvard University Press, Cambridge, Mass, USA, 1979.

[31] T. Hirschi, Causes of Delinquency, University of California Press, Berkeley, Calif, USA, 1969.

[32] P.-O. H. Wikström and D. Butterworth, Adolescent Crime: Individual Differences and Life Styles, Willan Publishing, Cambridge, UK, 2006.

[33] L. Brännström, Phantom of the Neighbourhood: Longitudinal Studies on Area-Based Conditions and Individual Outcomes, Swedish Institute For Social Research Dissertation Series, Stockholm University, Stockholm, Sweden, 2006.

[34] T. Thorlindsson and J. G. Bernburg, "Durkheim's theory of social order and deviance: a multi-level test," European Sociological Review, vol. 20, no. 4, pp. 271-285, 2004.

[35] F. Fariña, R. Arce, and M. Novo, "Neighborhood and community factors: effects on deviant behavior and social competence," Spanish Journal of Psychology, vol. 11, no. 1, pp. 78-84, 2008.

[36] J. G. Bernburg and T. Thorlindsson, "Community structure and adolescent delinquency in Iceland: a contextual analysis," Criminology, vol. 45, no. 2, pp. 415-444, 2007.

[37] D. Oberwittler, "Stadtstruktur, freundeskreise und delinquenz. Eine mehrebenenanalyse zu sozialökologischen kontexteffekten auf schwere jugenddelinquenz," in Soziologie Der Kriminalität, D. Oberwittler and S. Karstedt, Eds., pp. 135170, Vs Verlag für Sozialwissenschaften, Wiesbaden, Germany, 2004.

[38] E. Sellström and S. Bremberg, "Is there a "school effect" on pupil outcomes? A review of multilevel studies," Journal of Epidemiology and Community Health, vol. 60, no. 2, pp. 149155, 2006.

[39] C. Baerveldt, "Schools and the prevention of petty crime: search for a missing link," Journal of Quantitative Criminology, vol. 8, no. 1, pp. 79-94, 1992.

[40] G. C. Ousey and P. Wilcox, "Subcultural values and violent delinquency: a multilevel analysis in middle schools," Youth Violence and Juvenile Justice, vol. 3, no. 1, pp. 3-22, 2005.

[41] D. Oberwittler, "The effects of ethnic and social segregation on children and adolescents: recent research and results from a german multilevel study," Discussion Paper Sp Iv 2007-603, Social Science Research Centre Berlin, Berlin, Germany, 2007.
[42] H. Goldstein, Multilevel Statistical Models, Edward Arnold, London, UK, 2nd edition, 1995.

[43] T. M. Kauppinen, "Schools as mediators of neighbourhood effects on choice between vocational and academic tracks of secondary education in Helsinki," European Sociological Review, vol. 24, no. 3, pp. 379-391, 2008.

[44] H. Goldstein, "Multilevel cross-classified methods," Sociological Methods and Research, vol. 22, no. 3, pp. 364-375, 2006.

[45] J. Rasbah and H. Goldstein, "Efficient analysis of mixed hierarchical and cross-classified random structures using a multilevel model," Journal of Educational and Behavioral Statistics, vol. 19, no. 3, pp. 337-350, 1994.

[46] H. Brutsaert, Co-Educatie: Studiekansen en Kwaliteit van het Schoolleven, Garant, Leuven, Belgium, 2001.

[47] R. J. Sampson and D. J. Bartusch, "Legal cynicism and (subcultural?) Tolerance of deviance: the neighborhood context of racial differences," Law and Society Review, vol. 32, no. 4, pp. 777-804, 1998.

[48] P. O. H. Wikström and R. Loeber, "Do disadvantaged neighborhoods cause well-adjusted children to become adolescent delinquents? A study of male juvenile serious offending, individual risk and protective factors, and neighborhood context," Criminology, vol. 38, no. 4, pp. 1109-1140, 2000.

[49] T. Snijders and R. Bosker, Multilevel Analysis. An Introduction to Basic and Advanced Multilevel Modeling, Sage, London, UK, 1999.

[50] G. J. N. Bruinsma, Geografische Mobiliteit En Misdaad, Universiteit Leiden, Leiden, The Netherlands, 2000.

[51] R. Svensson and L. Pauwels, "Is a risky lifestyle always "risky"? The interaction between individual propensity and lifestyle risk in adolescent offending: a test in two urban samples," Crime and Delinquency, vol. 56, no. 4, pp. 608-626, 2010.

[52] R. J. Sampson, "Moving to inequality: neighborhood effects and experiments meet social structure," American Journal of Sociology, vol. 114, no. 1, pp. 189-231, 2008.

[53] P.-O. H. Wikström and M. Torstensson, "Local crime prevention and its national support: organisation and direction," European Journal on Criminal Policy and Research, vol. 7, no. 4, pp. 459-481, 1999.

[54] N. Declerck and L. Pauwels, Individu, Omgeving en de Verklaring van Jeugdcrimineel Gedrag. Een Toets in Twee Stedelijke Settings, Maklu, Antwerp, Belgium, 2000.

[55] J. Ludwig, G. J. Duncan, and P. Hirschfield, "Urban poverty and juvenile crime: evidence from a randomized housingmobility experiment," Quarterly Journal of Economics, vol. 116, no. 2, pp. 655-679, 2001.

[56] H. G. Grasmick, C. R. Tittle, R. J. Bursik, and B. J. Arneklev, "Testing the core empirical implications of Gottfredson and Hirschi's general theory of crime," Journal of Research in Crime and Delinquency, vol. 30, no. 1, pp. 5-29, 1993.

[57] M. G. Turner and A. R. Piquero, "The stability of self-control," Journal of Criminal Justice, vol. 30, no. 6, pp. 457-471, 2002.

[58] A. T. Vazsonyi, L. E. Pickering, M. Junger, and D. Hessing, "An empirical test of a general theory of crime: a fournation comparative study of self-control and the prediction of deviance," Journal of Research in Crime and Delinquency, vol. 38, no. 2, pp. 91-131, 2001.

[59] R. Agnew, "The interactive effects of social control variables on delinquency," in Control Theories of Crime and Delinquency. Advances in Criminological Theory, C. L. Britt and M. R. Gottfredson, Eds., vol. 12, pp. 53-76, Transaction, New Brunswick, NJ, USA, 2003. 
[60] C. L. Chapple, J. A. McQuillan, and T. A. Berdahl, "Gender, social bonds, and delinquency: a comparison of boys' and girls' models," Social Science Research, vol. 34, no. 2, pp. 357 383, 2005.

[61] R. Agnew and D. M. Peterson, "Leisure and delinquency," Social Problems, vol. 36, pp. 332-350, 1989.

[62] J. G. Bernburg and T. Thorlindsson, "Routine activities in social context: a closer look at the role of opportunity in deviant behavior," Justice Quarterly, vol. 18, no. 3, pp. 543$567,2001$.

[63] J. L. Mahoney and H. Stattin, "Leisure activities and adolescent antisocial behavior: the role of structure and social context," Journal of Adolescence, vol. 23, no. 2, pp. 113-127, 2000.

[64] K. B. Novak and L. A. Crawford, "Routine activities as determinants of gender differences in delinquency," Journal of Criminal Justice, vol. 38, no. 5, pp. 913-920, 2010.

[65] D. W. Osgood and A. L. Anderson, "Unstructured socializing and rates of delinquency," Criminology, vol. 42, no. 3, pp. 519549, 2004.

[66] D. W. Osgood, J. K. Wilson, P. M. O’Malley, J. G. Bachman, and L. D. Johnston, "Routine activities and individual deviant behavior," American Sociological Review, vol. 61, no. 4, pp. 635-655, 1996.

[67] S. Gsir, Housing and Segregation of Migrants-Case study, Eurofont Publications, Antwerp, Belgium, 2009. 


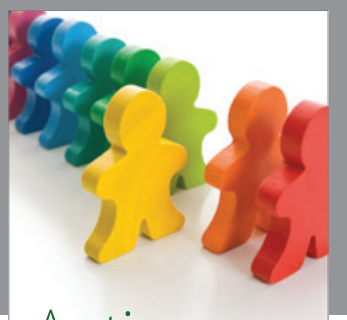

Autism

Research and Treatment
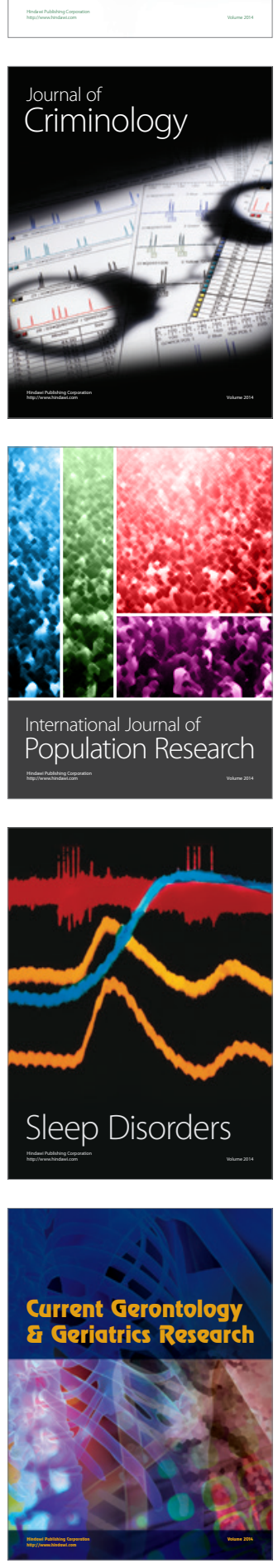
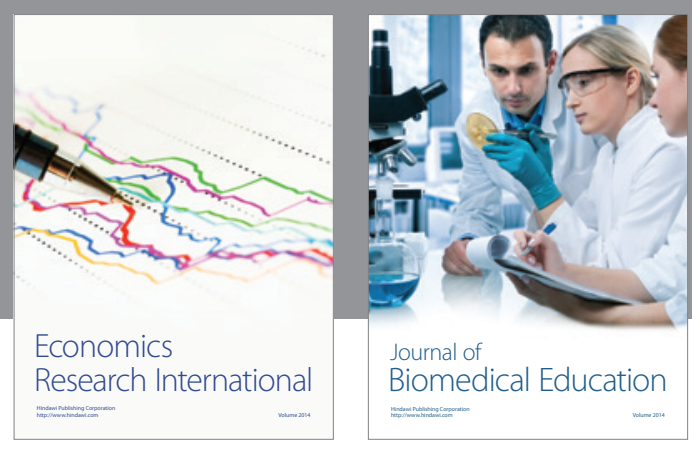

Journal of

Biomedical Education

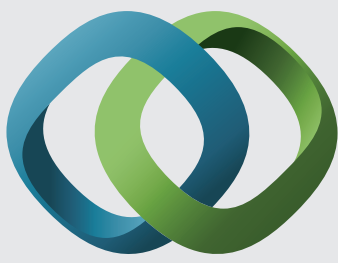

\section{Hindawi}

Submit your manuscripts at

http://www.hindawi.com
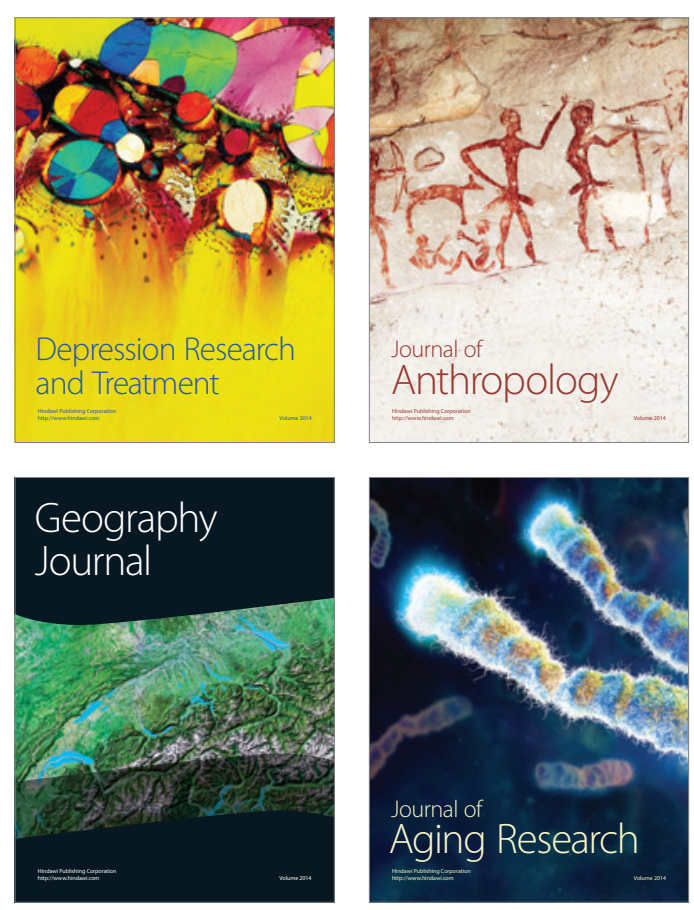

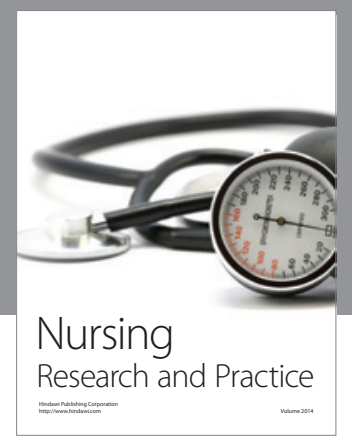

Nursing

Research and Practice

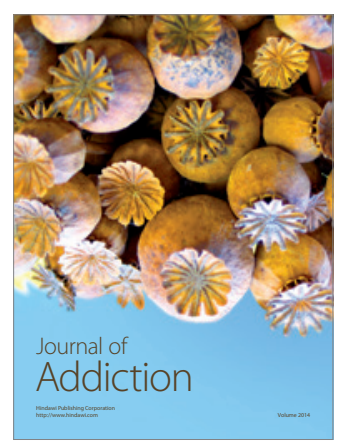

Child Development

Research

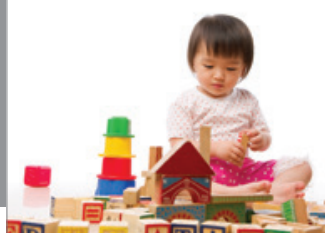

迥
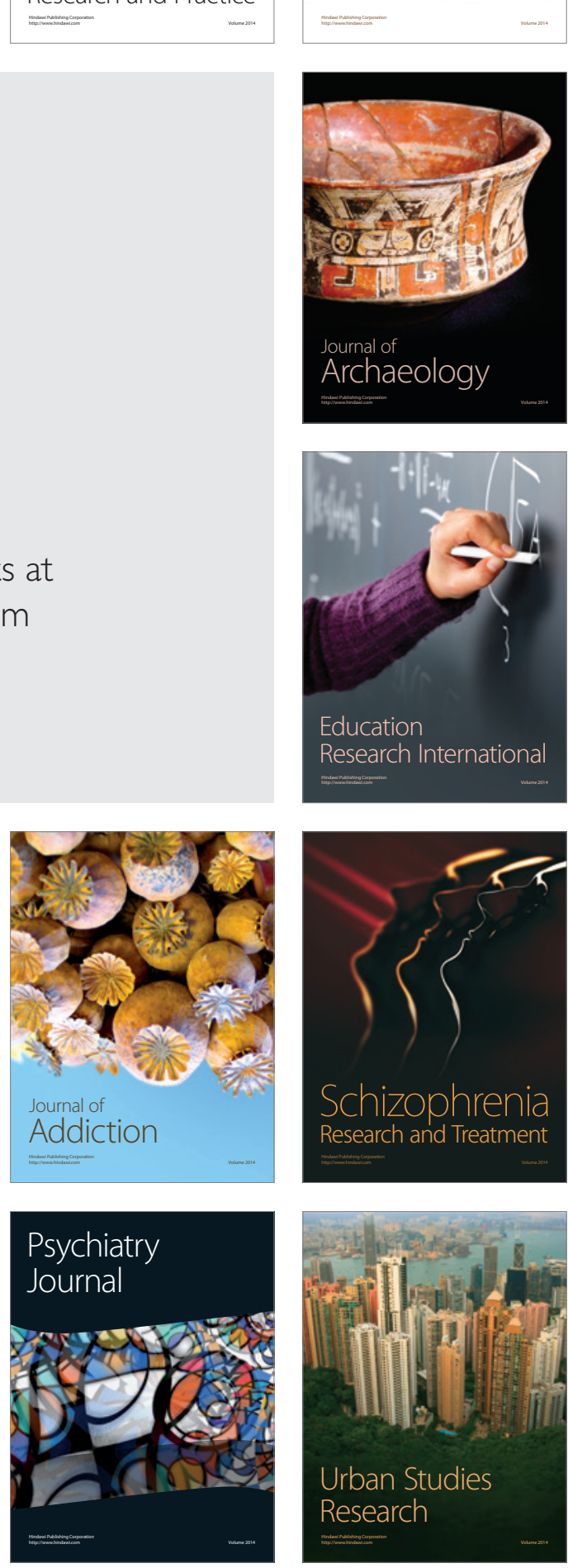